Gazi University
Journal of Science
http://dergipark.gov.tr/gujs

\title{
A Study on Hydrothermal Grown CdS Nanospheres: Effects of Cd/S Molar Ratio
}

\author{
Salih YILMAZ ${ }^{1 *}$ (D), Murat TOMAKIN ${ }^{2}$ (D) Ahmet UNVERDI $^{3}$ (D) Abdulaziz ABOGHALON $^{1}$ (D) \\ ${ }^{1}$ Department of Materials Engineering, Faculty of Engineering, Adana Alparslan Türkeş Science and Technology University, 01250, Adana, \\ Turkey \\ ${ }^{2}$ Department of Physics, Faculty of Arts and Sciences, Recep Tayyip Erdogan University, Rize, Turkey \\ ${ }^{3}$ Nanotechnology and Engineering Sciences, Graduate School of Natural and Applied Sciences, Adana Alparslan Türkeş Science and \\ Technology University, 01250, Adana, Turkey
}

\author{
Highlights \\ - CdS nanospheres were grown by hydrothermal route on glass slides. \\ -XRD results showed the existence of nano-amorphous CdS structure. \\ -The sphere size of CdS samples enhanced with increasing of $\mathrm{Cd} / \mathrm{S}$ molar ratio up to 1:3. \\ -More transparent $\mathrm{CdS}$ nanospheres were obtained for $\mathrm{Cd} / \mathrm{S}$ molar ratio of 1:3. \\ -The specimen with $\mathrm{Cd} / \mathrm{S}$ molar ratio of 1:3 exhibited the best electrical properties.
}

\begin{tabular}{l} 
Article Info \\
\hline \\
Received: $16 / 01 / 2019$ \\
Accepted: 20/06/2019 \\
Keywords \\
\hline CdS nanospheres \\
Hydrothermal method \\
SEM \\
Aptical properties \\
Electrical data
\end{tabular}

\begin{abstract}
The study reports the influences of altering of $\mathrm{Cd} / \mathrm{S}$ molar ratio on some physical properties of hydrothermal grown $\mathrm{CdS}$ nanospheres. $\mathrm{Cd} / \mathrm{S}$ molar ratios were chosen as 1:0.5, 1:1, 1:2, 1:3 and $1: 4$ in the stock solution. X-ray diffraction (XRD) data showed the occurrence of nano-amorphous CdS structure. Scanning electron microscopy (SEM) conclusions illustrated that increasing $\mathrm{Cd} / \mathrm{S}$ molar ratio up to 1:3 caused a growth in the sphere size whereas further rising of $\mathrm{Cd} / \mathrm{S}$ molar ratio led to smaller sphere size. The presence of $\mathrm{Cd}$ and $\mathrm{S}$ atoms in CdS structure was approved by Energy dispersive $\mathrm{x}$-ray spectroscopy (EDS) analysis. Optimum transparency was found by $\mathrm{Cd} / \mathrm{S}$ molar ratio of 1:3. Band gap scores of CdS nanospheres were determined to be above $2.60 \mathrm{eV}$ that was bigger than bulk $\mathrm{CdS}(2.42 \mathrm{eV})$ because of quantum confinement effect. Photoluminescence (PL) results showed that a gradual decrease in each peak was attained upon increasing $\mathrm{Cd} / \mathrm{S}$ molar ratio, which could be due to the formation non-radiative recombination phenomenon. Electrical data demonstrated that $\mathrm{CdS}$ nanosphere having $\mathrm{Cd} / \mathrm{S}$ molar ratio of $1: 1$ exhibited the best carrier density $\left(1.48 \times 10^{15} \mathrm{~cm}^{-3}\right)$ and resistivity $\left(1.27 \times 10^{3} \Omega . \mathrm{cm}\right)$ values. Thus, it can be deduced that $\mathrm{Cd} / \mathrm{S}$ molar ratio of 1:3 was obtained to be optimum one since it possesses both bigger sphere size and better transparency, facilitating the effective use of CdS nanospheres in the solar cells.
\end{abstract}

\section{INTRODUCTION}

CdS has recently attracted significant interest for its broad use in many application areas such as photosensors [1] and light emitting diodes (LEDs) [2]. CdS also emerges as a window layer material in solar cells including inorganic- and hybrid-based owing to its wide band gap, n-type conductivity, high electron affinity in addition to high photoconductivity and high absorption coefficient [3-5]. It has been already proven that $\mathrm{CdS}$ nanomaterials are one of the most appropriate for opto-electronic applications compared to their counterparts like thin films or bulks [4]. Additionally, they offer impressive photo-chemical and photo-physical properties due to the particle size effect $[4,6]$. 
CdS nanomaterials can be fabricated by diverse methods such as thermal evaporation [7], solvothermal process [8], solvent thermal process [9] and hydrothermal method [10] in the morphologies of nanorods, nanowires, nanospheres and nanoflowers, respectively. Hydrothermal method is an effortless, moderate, more environmental and more practical method than the others and it is an important method for synthesis of nanostructures at relatively low temperatures. The hydrothermal technique employs a solvent under the temperature and pressure above its crucial point to accelerate reactions and to boost the solubility of solids. The as-prepared nanostructures are well crystallized under the pressure caused by the hydrothermal reaction $[11,12]$. To prepare CdS nanomaterials by this route with good optical and electrical properties, it is crucial to control of $\mathrm{Cd} / \mathrm{S}$ molar ratio during the synthesis process.

It has seen from literature survey that hai of works on the synthesis of CdS nanostructures were done [1315], the density of works on the improving physical properties of $\mathrm{CdS}$ materials varying of $\mathrm{Cd} / \mathrm{S}$ molar ratio has remained limited. For instance, Pandya and co-workers produced CdS thin films by a dip coating route on glass slides. They reported the effects of modifying of $\mathrm{Cd} / \mathrm{S}$ molar ratio on structural, morphological and optical properties of grown CdS thin films [16]. Kumar and co-workers reported some physical properties as well as photocatalytic application of $\mathrm{SnO}_{2} / \mathrm{CdS}$ structure varying $\mathrm{Cd} / \mathrm{S}$ molar ratio and found that $\mathrm{SnO}_{2} / \mathrm{CdS}$ structure exhibited high photocatalytic ability [17]. Yuan et al. synthesized CdS nanoparticles by a new approach and examined the influence of variation in the $\mathrm{Cd} / \mathrm{S}$ molar ratio on particle size and photocatalytic properties. They obtained that increasing sulfur content in CdS led to larger particle size [18]. Xiao and co-workers prepared CdS nanocrystals by one-step synthesis route and investigated the role of $\mathrm{Cd} / \mathrm{S}$ molar ratio on photoluminescence properties of $\mathrm{CdS}$ samples [19]. On the other hand, Thambidurai et al. grew nanocrystalline CdS thin films by spray pyrolysis on glass substrates and examined the influences of altering $\mathrm{Cd} / \mathrm{S}$ molar ratio on structural and optical properties of $\mathrm{CdS}$ thin films [20]. However, to the best of our knowledge, there is no work examining the variation of $\mathrm{Cd} / \mathrm{S}$ ratio for $\mathrm{CdS}$ nanospheres prepared by hydrothermal method. It is known that the growth of the CdS material in the nanomorphology causes an enlargement in the forbidden band gap of CdS because of quantum confinement effect [21], yielding the match of incoming photons to the spectral efficiency of the solar cells [20]. Therefore, we present a work on improving some physical properties of $\mathrm{CdS}$ nanospheres grown by hydrothermal route on glass slides. To succeed this aim, CdS nanospheres are prepared by different molar ratios of 1:0.5 (S1), 1:1 (S2), 1:2 (S3), 1:3 (S4) and 1:4 (S5) in order to obtain the optimum Cd/S molar ratio. Thus, we examine the effects of modifying $\mathrm{Cd} / \mathrm{S}$ molar ratio on structural, morphological, optical and electrical properties of hydrothermal grown $\mathrm{CdS}$ nanospheres for the first time in this paper.

\section{EXPERIMENTAL PROCESS}

\subsection{Synthesis of CdS nanospheres}

A hydrothermal route was employed to grow CdS nanospheres on glass substrates. Cleaning procedure of the substrates is in turn applied by sulfuric acid, distilled water and ethanol in an ultrasonic bath for 10 mins and then the surfaces of the substrates were dried by a nitrogen gas flow. To synthesize CdS nanospheres, stock solution including $\left(\mathrm{Cd}\left(\mathrm{NO}_{3}\right)_{2} \cdot 4 \mathrm{H}_{2} \mathrm{O}\right)$, thiourea $\left(\left(\mathrm{NH}_{2}\right)_{2} \mathrm{CS}\right)$ and glutathione used as starting materials were prepared. For the synthesis process, five different specimens which were labeled as S1, S2, S3, S4 and S5 associated with Cd/S molar ratio of 1:0.5, 1:1, 1:2, 1:3 and 1:4, respectively. Cd/glutathione molar ratio was adjusted as 1:0.6 during the synthesis of all the samples. For the preparation of the starting solution, adequate amounts of cadmium nitrate, thiourea and glutathione materials were individually dissolved in the distilled water solution $(20 \mathrm{ml})$. Subsequently, these solutions were spilled into a teflonbeaker and then to obtain the final solution $(75 \mathrm{ml})$, sufficient amount of distilled water was added. Cleaned glass substrates were then vertically placed to the bottom of teflon-beaker located inside of the stainless steel autoclave. Then, it was sealed and heated up to $150^{\circ} \mathrm{C}$ by waiting at that temperature for $3.5 \mathrm{~h}$. Upon the deposition, the teflon-beaker was taken out from the autoclave and allowed naturally cool down the room temperature. After this process, grown samples were removed from the solution rinsing by distilled water for 2 mins and subsequently, they were dried by nitrogen gas. Upon the synthesis procedure, all the specimens were cut as pieces of $1.25 \mathrm{~cm}$ x $1.50 \mathrm{~cm}$ before the characterization. 


\subsection{Characterization}

X-ray diffraction (XRD) instrument (Rigaku SmartLab Unit) using a $\mathrm{Cu} \mathrm{K} \alpha$ radiation in the range of $10^{\circ}-$ $70^{\circ}$ was employed to structurally characterize the samples. Morphological analysis was done through scanning electron microscopy (SEM, JEOL JSM-6610) and field emission scanning electron microscopy (FE-SEM, FEI-Quanta 650) devices. Elementals compositional measurements were made using energy dispersive X-ray spectroscopy (EDS) attached to SEM. Transmittance curves are taken by Spectramax in the wavelength range of 300-1000 $\mathrm{nm}$. A Dongwoo Optron employing a Xe lamp with a power of $450 \mathrm{~W}$ was utilized to examine photoluminescence (PL) properties of the materials at room temperature. An excitation wavelength of this analysis was conducted by $280 \mathrm{~nm}$. Measurements of Hall effect and four probe method were carried out to electrically investigate the samples at room temperature to reach carrier density and resistivity, respectively.

\section{RESULTS AND DISCUSSION}

XRD data of S1 sample is shown in Figure 1. The XRD data of all the other samples exhibits exactly the same behavior; therefore, they aren't presented here. It is seen that S1 displays a wide peak in the range of $2 \theta=15^{\circ}-35^{\circ}$. This peak is ascribed to the nano-amorphous growth of CdS nanospheres because of the occurrence of CdS specimens with thickness of about $100 \mathrm{~nm}$ (will be discussed in SEM below). RodriguezRosales et al. reported an analogous outcome for CdS thin films produced on PET substrates by CBD route [22]. Apart from these peaks seen in the patterns, no peak associated with $\mathrm{CdS}$ and its compounds is detected within the detection limit of our XRD device.

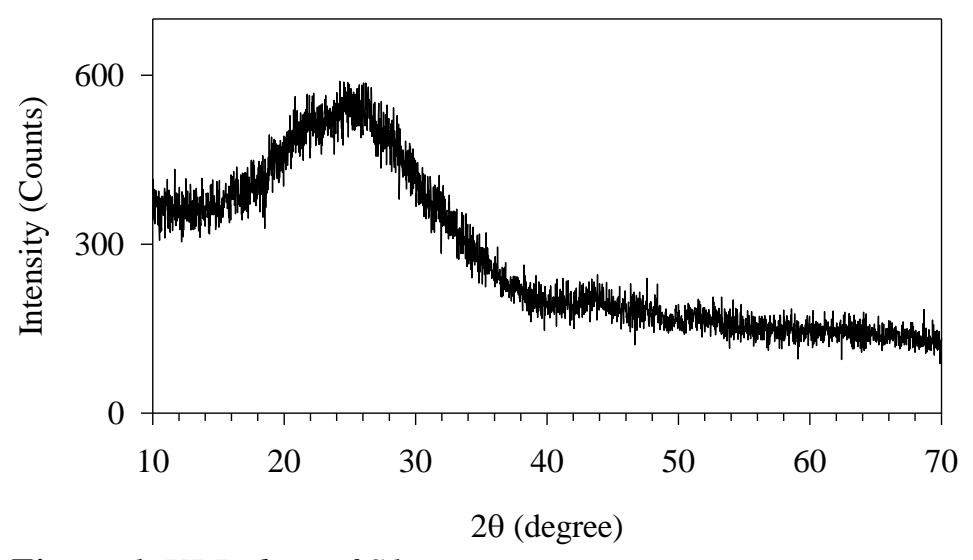

Figure 1. XRD data of S1 specimen

Plain view SEM images of S1, S2, S3, S4 and S5 specimens produced on glass substrates are indicated in Figure 2(a)-(e). Figure 2(a) shows SEM data of S1 sample, suggesting that nanoscaled sphere morphology is observed. A homogenous sphere distribution is seen besides the presence of the smallest sphere size. A compact and dense morphology is also reached without forming any crack or void. Additionally, big sized spheres come into existence over the smaller ones. When $\mathrm{Cd} / \mathrm{S}$ molar ratio is altered from 1:0.5 to 1:1 (as indicated in Figure 2(b)), sphere size starts increasing and undefined shape grains are also seen on the surface of the sample. Figure 2(c) depicts the morphology related to $\mathrm{Cd} / \mathrm{S}$ molar ratio of 1:2. It is appeared that obvious and compact topography in addition to the existence of uniform sphere distribution is acquired whereas some big spheres are still seen over the smaller ones. SEM data of S4 sample corresponding to $\mathrm{Cd} / \mathrm{S}$ molar ratio of 1:3 is demonstrated in Figure 2(d), proposing that this specimen possesses the largest sphere size in addition to its homogenous sphere size distribution. Yet, some big grains still seem on the surface. An enlargement in the sphere size with increasing sulfur ingredient till $\mathrm{Cd} / \mathrm{S}$ molar ratio of 1:3 in $\mathrm{CdS}$ could be ascribed to the highest growth regime of $\mathrm{CdS}$ nanosphere on glass substrates [23]. It was also reported that a rise in the sulfur atoms in $\mathrm{CdS}$ matrix led to a grain growth till a critical $\mathrm{Cd} / \mathrm{S}$ molar ratio [14]. Figure 2(e) represents SEM result of S5 specimen $(\mathrm{Cd} / \mathrm{S}$ molar ratio of 1:4). It is remarkable that sphere sizes substantially reduce even though their uniform distribution is preserved. More compact topography is also obtained. In comparison with the previous samples, further increase of sulfur atoms in 
CdS host matrix (S5) gives rise to a reduction in the sphere size which might be referred to the growth limitation of CdS nanospheres owing to the saturation of sulfur atoms in CdS structure [24, 14]. A declining behavior of sphere size with dropping $\mathrm{Cd} / \mathrm{S}$ molar ratio was also found by Zhao et al. for $\mathrm{CdS}$ thin films grown by CBD method [25] and Lopes et al. for CdS nanospheres synthesized by sonochemical technique [26]. Thickness evaluation is made through the cross-sectional measurement and the conclusion of S3 is provided in Figure 2(f), implying that average thickness of the sample is about $108 \mathrm{~nm}$. Figure 2(g) depicts FESEM top-view photograph of S4 specimen, proving an obvious creation of CdS nanospheres on the glass slides. It could be also noted from Figure $2(\mathrm{~g})$ that $\mathrm{CdS}$ nanospheres are formed by assembling of small nanocrystallites.
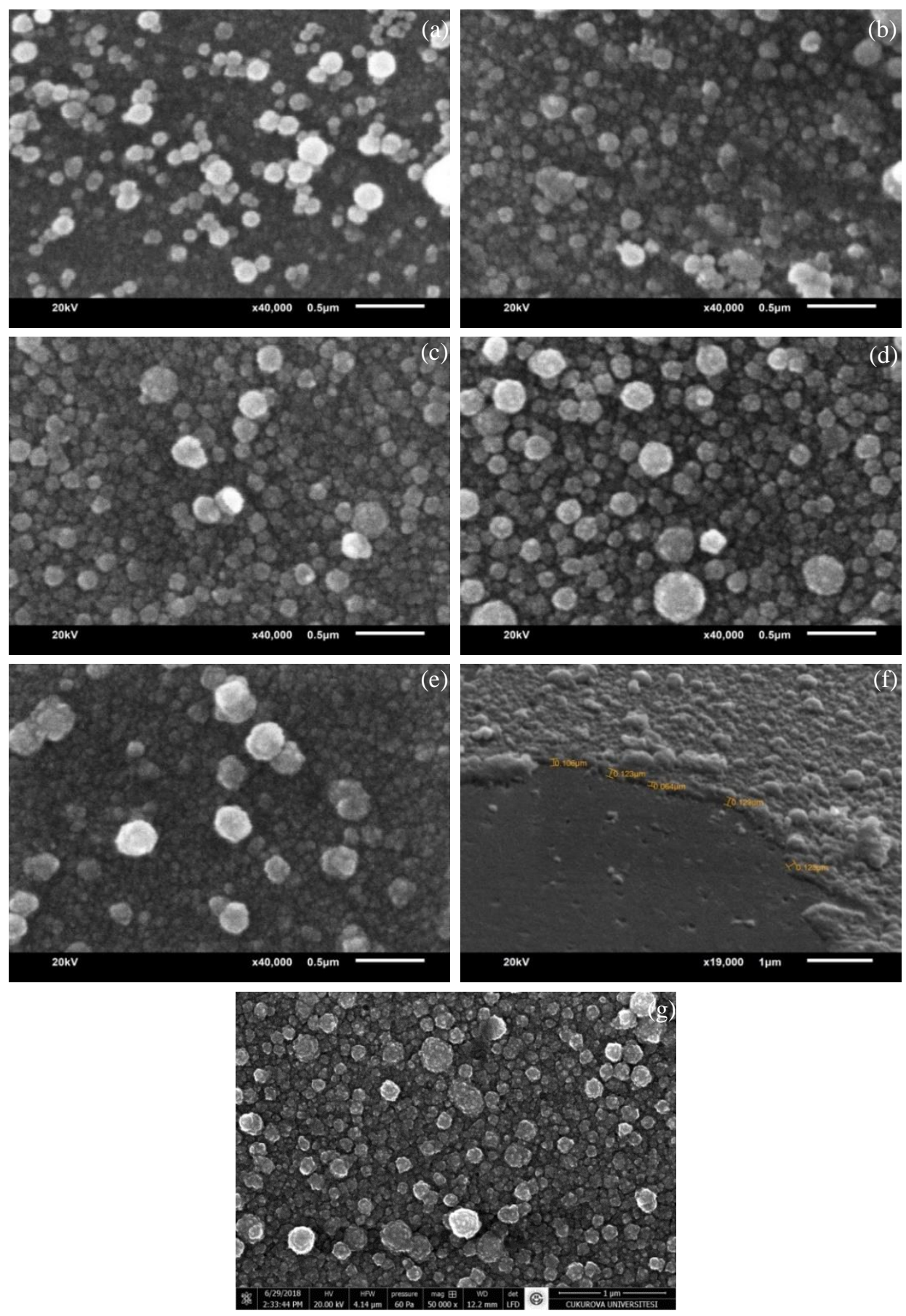

Figure 2. SEM plain view photographs of (a) S1, (b) S2, (c) S3, (d) S4 and (e) S5 specimens with a magnification 50000x. $(f)$ shows the cross-sectional image of S3. $(g)$ indicates FE-SEM top-view image of S4 
EDS survey spectra and true atomic concentrations (presented in the insets) of S1, S2, S3, S4 and S5 specimens produced on the glass slides are illustrated in Figure 3. The existence of $\mathrm{Cd}$ and $\mathrm{S}$ atoms in $\mathrm{CdS}$ structure is proved by these spectra. S1 sample has $\mathrm{Cd}$ and $\mathrm{S}$ atoms with an atomic ratio of 1.07. This ratio progressively diminishes with rising of $\mathrm{Cd} / \mathrm{S}$ molar ratio up to $1: 4$. The lowest $\mathrm{Cd} / \mathrm{S}$ atomic ratio of 0.91 is acquired for $\mathrm{Cd} / \mathrm{S}$ molar ratio of 1:4. It is attained that $\mathrm{CdS}$ nanospheres having $\mathrm{Cd} / \mathrm{S}$ molar ratio of 1:0.5 exhibit excess of cadmium and lack of sulfur atoms. Once $\mathrm{Cd} / \mathrm{S}$ molar ratio is dropped from 2 to 1 , the most stoichiometric sample is reached. Upon further reducing of $\mathrm{Cd} / \mathrm{S}$ molar ratio, sulfur rich and cadmium deficient specimens are obtained, implying that a divergence from the stoichiometry is found. It can be also declared that it seems an analogous behavior in the alteration between atomic and molar ratios of $\mathrm{Cd} / \mathrm{S}$ as anticipated.
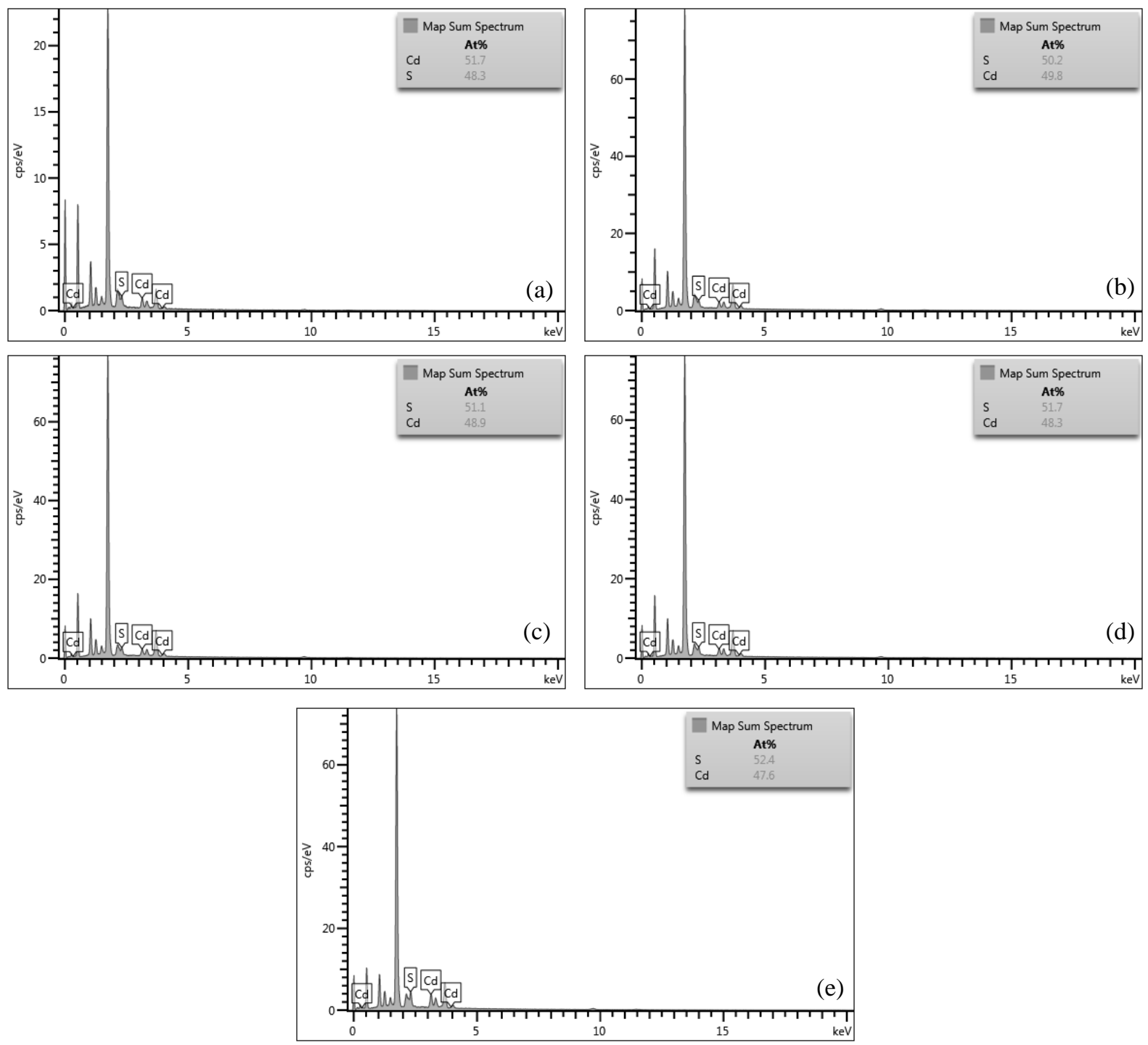

Figure 3. EDS data of (a) $S 1$, (b) $S 2$, (c) S3, (d) S4 and (e) S5 specimens. Insets of the figures indicate the true atomic concentrations of $C d$ and $S$ in the $C d S$ nanospheres

Transparency of CdS specimens is examined by transmission analysis and the conclusions of S1, S2, S3, S4 and S5 specimens are shown in Figure 4. S1 sample possesses a transmittance ( $T$ ) value of almost $51 \%$ in the wavelength interval of 550-800 $\mathrm{nm}$ and then $T$ takes the maximum score of $58 \%$ at $1000 \mathrm{~nm}$. When $\mathrm{Cd} / \mathrm{S}$ molar ratio is modified to 1:1 ( $\mathrm{S} 2$ specimen), transmission substantially decreases to about $42 \%$ and the highest $T$ of $48 \%$ at $1000 \mathrm{~nm}$ is acquired even though the curve shape is akin to that of S1 specimen. The deterioration in the transmittance could be attributed to the small alteration in the thickness values of the CdS nanospheres. Zhao et al. reported a similar result in the transmission of the specimens with 
increasing of $\mathrm{S} / \mathrm{Cd}$ molar ratio [25]. But, once $\mathrm{Cd} / \mathrm{S}$ molar ratio is changed to 1:2 (S3 specimen), transparency improves to $48 \%$ that is still lower than that of S1. On the other hand, S4 specimen associated with $\mathrm{Cd} / \mathrm{S}$ molar ratio of 1:3 exhibits the peak $T$ score of $55 \%$ in the wavelength range of $550 \mathrm{~nm}-850$ $\mathrm{nm}$. The enhancement in the transparency may be due to the growth in the sphere size as illustrated in Figure 2(d). Pandya and co-workers obtained an analogous data, saying that more transparent CdS thin films synthesized by CBD were attained with the rise of sulfur atoms in CdS specimens [19]. As the $\mathrm{Cd} / \mathrm{S}$ molar ratio is varied from $1: 3$ to $1: 4$, the transmittance plot exhibits moderately different behavior, especially at lower wavelength region. Furthermore, transparency of CdS nanosphere is got worse for S5 sample with respect to that of S4 one. This slight degradation in the transmission is ascribed to smaller sphere size as displayed in Figure 2(e). Eventually, it can be stated that the most transparent CdS nanosphere is reached for $\mathrm{S} 4$ sample that is able to be employed in the CdTe or CIGS-based solar cells as a window layer.

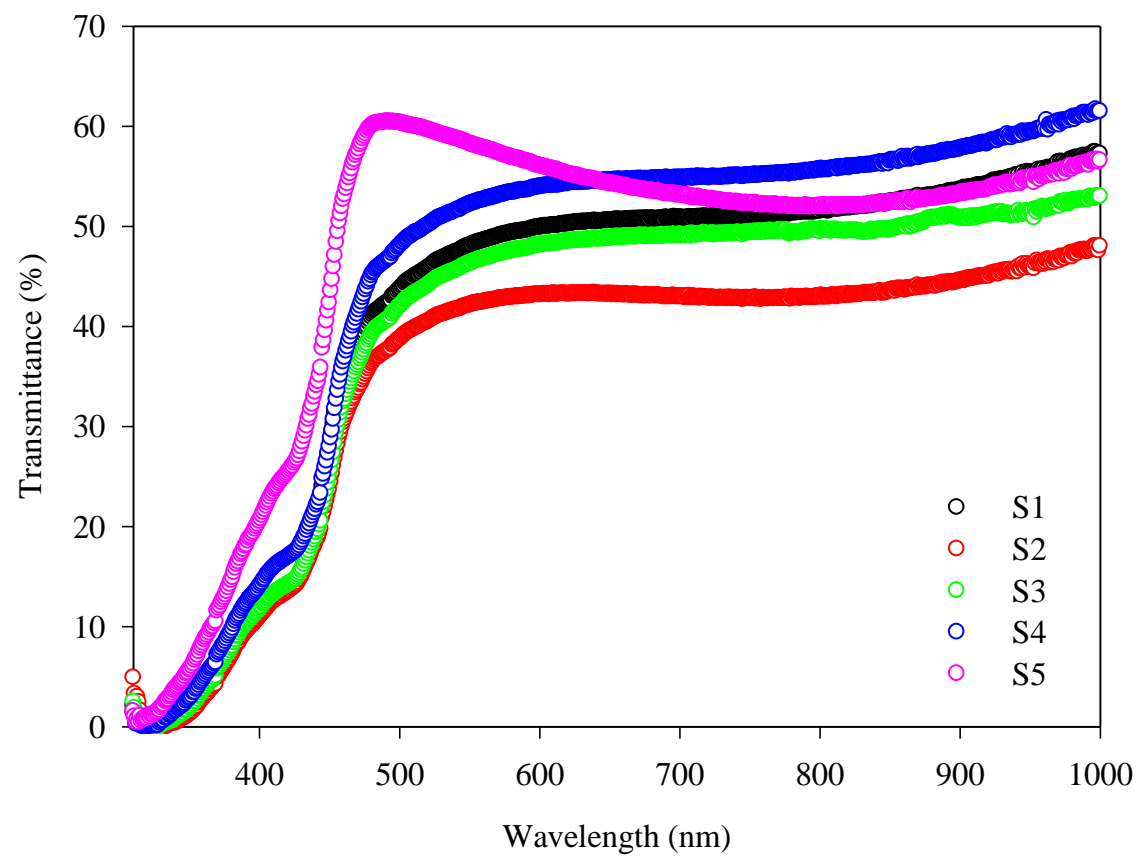

Figure 4. Transmittance plots of S1, S2, S3, S4 and S5 specimens

Upon reducing $\mathrm{Cd} / \mathrm{S}$ molar ratio, absorption edge moves to the longer wavelength region as can be shown in Figure 4. Band gaps of S1, S2, S3, S4 and S5 specimens are determined via Tauc's approximation [27] and the conclusions are given in Figure 5. It is obtained that all the samples exhibit forbidden band gaps above $2.60 \mathrm{eV}$ that is wider than that of bulk CdS $(2.42 \mathrm{eV})$. The reason for boosting of the band gap of $\mathrm{CdS}$ specimens is most probably due to the quantum size effect taking place at diminishing of the crystalline size below a critical value [21]. But, XRD outcomes indicate that $\mathrm{CdS}$ specimens grow in the nanoamorphous structure owing to formation in thin thickness (about $100 \mathrm{~nm}$ ) and thus, it is difficult to calculate the crystalline size of the specimens. On the other hand, as shown in Figure 2(g), CdS nanospheres are formed by agglomeration of nano-sized crystallites, implying that the crystallites possess a very small grain size. Forbidden band gap of $\mathrm{S} 1$ specimen is determined as $2.66 \mathrm{eV}$ and when $\mathrm{Cd} / \mathrm{S}$ molar ratio is modified to 1:1 (S2 specimen), it reduces to $2.61 \mathrm{eV}$. Zhao et al. grew CdS-based thin films and found that increasing $\mathrm{S} / \mathrm{Cd}$ molar ratio led to a reduction in the band gap of the samples, which is consistent with our outputs [25]. However, further decrease of $\mathrm{Cd} / \mathrm{S}$ molar ratio till 1:2 and 1:3 brings about a little increase in the band gap value of the specimens that is nearly $2.62 \mathrm{eV}$. On the other hand, a clear rise is attained for $\mathrm{S} 5$ specimen with a band gap of $2.66 \mathrm{eV}$ that is the same as that of $\mathrm{S} 1$. This significant variation in the band gap might be attributed to the presence of quantum confinement effect. 

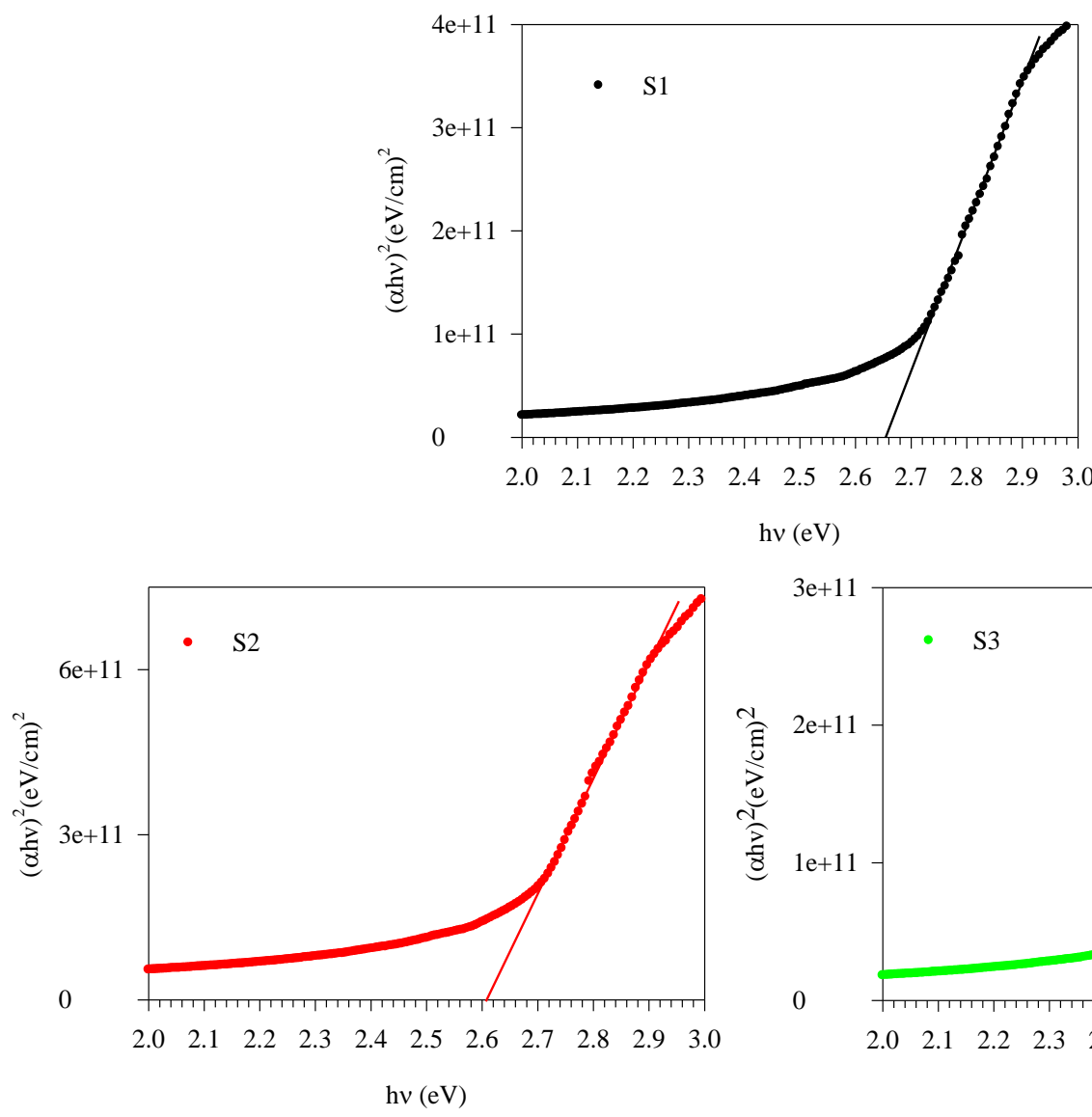

$\mathrm{h} v(\mathrm{eV})$
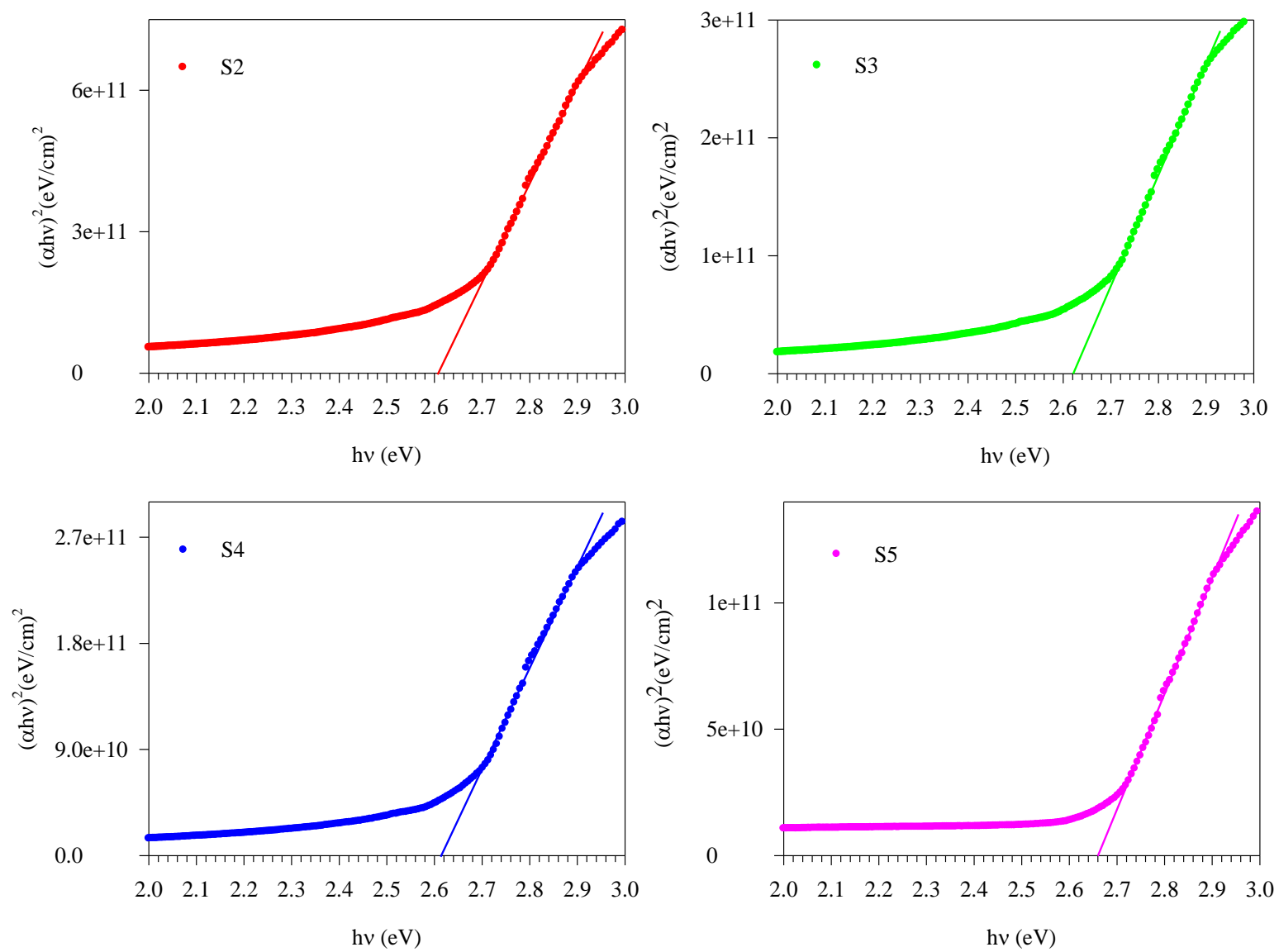

Figure 5. Tauc's curves of S1, S2, S3, S4 and S5 specimens

PL plots of S1, S2, S3, S4 and S5 specimens are demonstrated in Figure 6. It is noticeable that S1 sample principally has four essential peaks that are settled in the range of $350-450 \mathrm{~nm}, 400-500 \mathrm{~nm}, 500-550 \mathrm{~nm}$, $550-650 \mathrm{~nm}$ and $650-750 \mathrm{~nm}$ equaling to $\mathrm{UV}$, blue, green, yellow and red bands, respectively. It is known that the nonstoichiometric growth of CdS specimen leads to the creation of some intrinsic defects including cadmium interstitial $\left(\mathrm{I}_{\mathrm{Cd}}\right)$, cadmium vacancy $\left(\mathrm{V}_{\mathrm{Cd}}\right)$, sulfur interstitial $\left(\mathrm{I}_{\mathrm{S}}\right)$ and sulfur vacancy $\left(\mathrm{V}_{\mathrm{S}}\right)$. While UV peak is related to the transitions from deep to shallow levels, blue peak is ascribed to defect states [28]. Furthermore, according to our Tauc's conclusions, band gaps of CdS nanospheres are above $2.60 \mathrm{eV}$, which corresponds to blue band of PL plots whereas bulk value of CdS $(2.42 \mathrm{eV})$ equals to the green region in PL. On the other hand, our CdS specimens grow in the nanoscale size, approving that a shift to blue region in the wavelength owing to quantum confinement effect is attained in PL data. Hence, the blue peak might be also attributed to CdS band edge owing to the radiative recombination of excitons [20]. The green band is responsible for the electron transition between $V_{S}$ and $I_{S}$ levels [29]. The yellow peak is originating from 
the transition from valence band to $\mathrm{I}_{\mathrm{Cd}}$ defect levels while red band is imputed to the $\mathrm{V}_{\mathrm{Cd}}$ defects induced by surface states [30]. As Cd/S molar ratio is altered, there seems no significant variation in the shape of the curves. Yet, PL intensity of the CdS nanospheres progressively diminishes with rising of sulfur atoms in $\mathrm{CdS}$ structure, proposing that sulfur atoms cause an annihilation behavior in the PL intensity. This means that non-radiative recombination processes might be triggered by increasing of sulfur atoms in $\mathrm{CdS}$. Xiao et al. reported a similar character in the PL conclusion with the boost of S atoms in CdS nanocrystals [19]. Moreover, the reason for the reduction in the PL intensity may be associated with some possible recombination between intrinsic defects, leading to the annihilation of above mentioned defects in $\mathrm{CdS}$ nanospheres.

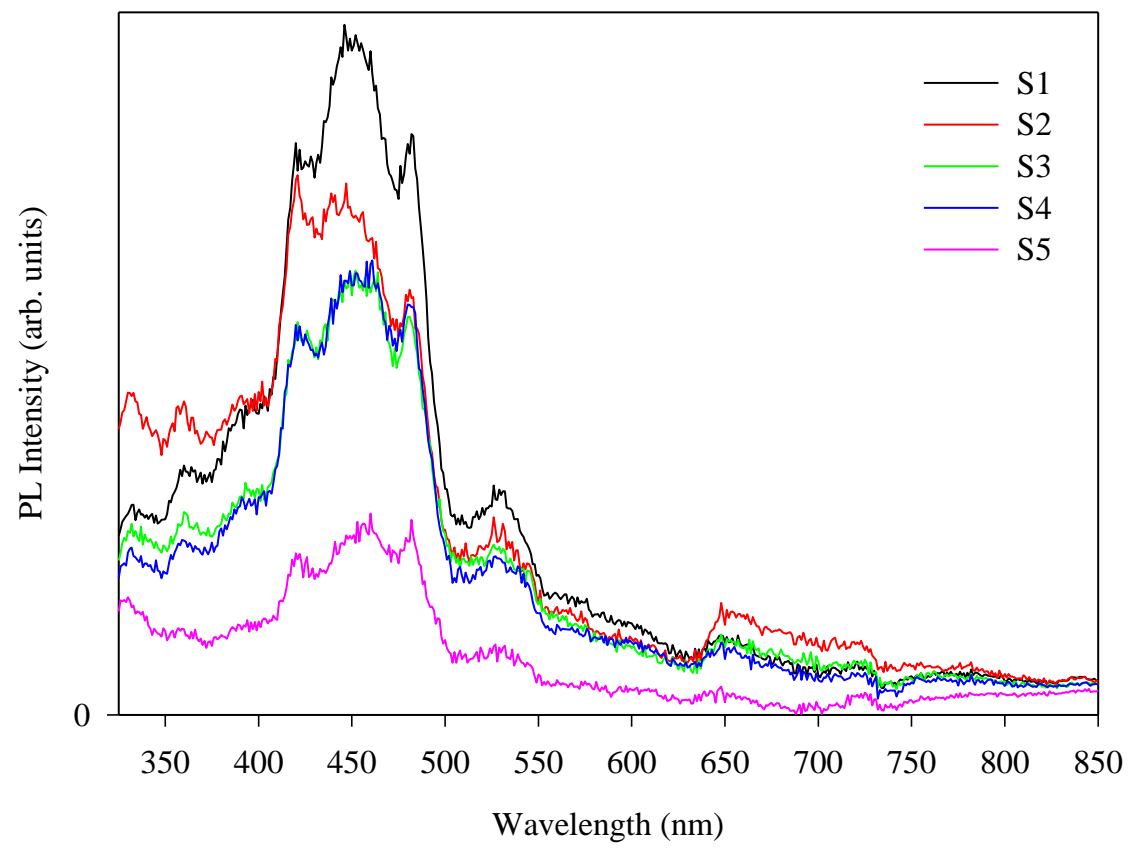

Figure 6. RTPL plots of $S 1, S 2, S 3, S 4$ and $S 5$ specimens

XRD and EDS (argued above) data showed no clear evidence in the formation of CdS structure because the results of both data aren't enough to reveal the existence of CdS. However, according to the optical conclusions (transmittance, Tauc's curve analysis and PL), one can say the creation of CdS samples due to the presence of absorption edge and band gap value as well as occurrence of some peaks associated with intrinsic defects of $\mathrm{CdS}$, respectively.

Carrier concentrations and resistivities of S1, S2, S3, S4 and S5 specimens are tabulated in Table 1. It is obtained that S1 sample has a carrier density $(n) 5.42 \times 10^{14} \mathrm{~cm}^{-3}$ and a resistivity $(\rho)$ of $3.01 \times 10^{3} \Omega . \mathrm{cm} . n$ score improves to $1.48 \times 10^{15} \mathrm{~cm}^{-3}$ and $\rho$ score reduces to $1.27 \times 10^{3} \Omega . \mathrm{cm}$ with varying of $\mathrm{Cd} / \mathrm{S}$ molar ratio till 1:1. Enhancement of these values might be ascribed to increasing of sulfur atoms in $\mathrm{CdS}$ as discussed in Figure 3. On the other hand, the decrement in the resistivity could be referred to rising of carrier density accordingly. Cruz and co-workers found that lower amount of S/Cd molar ratio remarkably dropped the resistivity of $\mathrm{CdS}$ thin films whereas further increment of $\mathrm{S} / \mathrm{Cd}$ molar ratio brought about a boost in the resistivities of the specimens [31]. But, when the molar ratio is changed further, a successive decrease appears in the $n$ scores and a gradual increment in the $\rho$ scores as collected in Table 1. This degradation in the electrical properties of CdS nanospheres could be related to diminishing of the mobility of the carriers owing to the occurrence of more S atoms in CdS structure (as debated in EDS outcomes), leading to the creation of trapping centers [32]. 
Table 1. Carrier concentrations and resistivities of S1, S2, S3, S4 and S5 specimens

\begin{tabular}{|l|l|l|}
\hline Sample & Carrier concentration $\left(\mathrm{cm}^{-3}\right)$ & Resistivity $(\Omega . \mathrm{cm})$ \\
\hline S1 & $5.42 \times 10^{14}$ & $3.01 \times 10^{3}$ \\
\hline S2 & $1.48 \times 10^{15}$ & $1.27 \times 10^{3}$ \\
\hline S3 & $6.55 \times 10^{14}$ & $3.15 \times 10^{3}$ \\
\hline S4 & $5.21 \times 10^{14}$ & $3.21 \times 10^{3}$ \\
\hline S5 & $3.02 \times 10^{14}$ & $3.40 \times 10^{3}$ \\
\hline
\end{tabular}

\section{CONCLUSIONS}

CdS nanospheres were successfully prepared by the hydrothermal route on glass slides. The change of $\mathrm{Cd} / \mathrm{S}$ molar ratio played a vital role on morphology, transparency, band gap, photoluminescence and electrical characteristic of $\mathrm{CdS}$ nanospheres. A nano-amorphous structure was attained from XRD data. SEM results showed that a rise in the sphere size was observed till $\mathrm{Cd} / \mathrm{S}$ molar ratio of 1:3 and then, sphere size reduced. Also, more homogeneous samples' surfaces were reached with the decrease $\mathrm{Cd} / \mathrm{S}$ molar ratio. It was found that $\mathrm{S} 1$ specimen had an atomic ratio of 1.07 whereas this value reduced up to S4 specimen attaining the lowest value of 0.91 . In addition, the variation of molar ratio of $\mathrm{CdS}$ led to an improvement in the transparency, particularly for $\mathrm{Cd} / \mathrm{S}$ molar ratio of $1: 3$. It was calculated that $\mathrm{CdS}$ specimens possessed forbidden band gaps above $2.60 \mathrm{eV}$. RTPL data displayed that rising sulfur atoms in CdS structure caused a reduction in the intensity of PL peaks. The optimum electrical data was acquired for $\mathrm{Cd} / \mathrm{S}$ molar ratio of 1:1. It can be concluded that $\mathrm{Cd} / \mathrm{S}$ molar ratio of $1: 3$ was decided to be the best one due to exhibiting larger sphere size and best transparency, which can be efficiently utilized in thin film-based solar cells as a window layer.

\section{CONFLICTS OF INTEREST}

No conflict of interest was declared by the authors.

\section{REFERENCES}

[1] Gosavi, S.R., Nikam, C.P., Shelke, A.R., Patil, A.M., Ryu, S.W., Bhat, J.S., Deshpande, N.G., "Chemical synthesis of porous web-structured CdS thin films for photosensor applications", Materials Chemistry and Physics, 160: 244-250, (2015).

[2] Heiba, Z.K., Mohamed, M.B., Imam, N.G., "Fine-tune optical absorption and light emitting behavior of the CdS/PVA hybridized film nanocomposite", Journal of Molecular Structure, 1136: 321-329, (2017).

[3] Wang, W., Liu, Z., Wang, G., "Synthesis of CdS nanoparticles by a novel and simple one-step, solid state reaction in the presence of nonionic surfactant", Materials Letters, 57(18): 2755-2760, (2003).

[4] Rao, B.S., Kumar, B.R., Reddy, V.R., Rao, T.S., "Preparation and characterization of CdS nanoparticles by chemical co-precipitation technique", Chalcogenide Letters, 8(3): 177-185, (2011).

[5] Junkermeier, C.E., Lewis, J.P., Bryant, G.W., "Amorphous nature of small CdS nanoparticles: molecular dynamics simulations", Physical Review B, 79(12): 125323-1253231, (2009).

[6] Mazumder, S., Dey, R., Mitra, M.K., Mukherjee, S., Das, G.C., "Review: biofunctionalized Quantum Dots in Biology and Medicine", Journal of Nanomaterials, 2009: 1-17, (2009). 
[7] Baghchesara, M.A., Yousefi, R., Cheraghizade, M., Sheini, F.J., Saaedi, A., "Photocurrent application of Zn-doped CdS nanostructures grown by thermal evaporation method", Ceramics International, 42(1): 1891-1896, (2016).

[8] Zhao, J.G., Hua, Z.H., Yao, Y., "Solvothermal synthesis and characterization of one-dimensional CdS nanowires", Superlattices and Microstructures, 61: 146-151, (2013).

[9] Guo, X., Chen, C., Song, W., Wang, X., Di, W., Qin, W., “CdS embedded $\mathrm{TiO}_{2}$ hybrid nanospheres for visible light photocatalysis", Journal of Molecular Catalysis A: Chemical, 387: 1-6, (2014).

[10] Wang, Y., Yang, X., Ma, Q., Kong, J., Jia, H., Wang, Z., Yu, M., "Preparation of flower - like CdS with SDBS as surfactant by hydrothermal method and its optical properties", Applied Surface Science, 340: 18-24, (2015).

[11] Tang, K.B., Qian, Y.T., Zeng, J.H., Yang, X.G., "Solvothermal Route to Semiconductor Nanowires", Advanced Materials, 15: 448-450, (2003).

[12] Niasari, M.S., Estarki, M.R.L., Davar, F., "Controllable synthesis of nanocrystalline CdS with different morphologies by hydrothermal process in the presence of thioglycolic acid", Chemical Engineering Journal, 145(2): 346-350, (2008).

[13] Zhai, T., Fang, X., Li, L., Bando, Y., Golberg, D., "One-dimensional CdS nanostructures: synthesis, properties, and applications", Nanoscale, 2: 168-187, (2010).

[14] Datta, A., Kar, S., Ghatak, J., Chaudhuri, S., "Solvothermal synthesis of CdS nanorods: Role of basic experimental parameters", Journal of Nanoscience and Nanotechnology, 7(2): 677-688, (2007).

[15] Vazquez, A., Serrano, T., Kharisov, B., Gomez, I., "Morphological control of cadmium sulfide nanostructures by electrophoretic deposition", Particuology, 24: 73-77, (2016).

[16] Pandya, S., Raval, K., "Investigation of structural, morphological and optical properties of cadmium sulphide (CdS) thin films at different $\mathrm{Cd} / \mathrm{S}$ concentration deposited by chemical technique", Journal of Materials Science: Materials in Electronics, 28(23): 18031-18039, (2017).

[17] Kumar, V., Rajaram, P., Goswami, Y.C., "Sol-gel synthesis of $\mathrm{SnO}_{2} / \mathrm{CdS}$ heterostructures using various Cd:S molar ratio solutions and its application in photocatalytic degradation of organic dyes", Journal of Materials Science: Materials in Electronics, 28(12): 9024-9031, (2017).

[18] Yuan, X., Li, M., Ruan, H., Yang, Y., Liu, Y., Zhang, L., "CdS nanoparticles with high photocatalytic property synthesized by a new liquid-liquid method", Journal of Materials Science: Materials in Electronics, 27(6): 6030-6034, (2016).

[19] Xiao, Q., Xiao, C., "Surface-defect-states photoluminescence in CdS nanocrystals prepared by onestep aqueous synthesis method", Applied Surface Science, 255(16): 7111-7114, (2009).

[20] Thambidurai, M., Murugan, N., Muthukumarasamy, N., Agilan, S., Vasantha, S., Balasundaraprabhu, R., "Influence of the $\mathrm{Cd} / \mathrm{S}$ Molar Ratio on the Optical and Structural Properties of Nanocrystalline CdS Thin Films", Journal of Materials Science \& Technology, 26(3): 193-199, (2010).

[21] Kumar, S., Sharma, P., Sharma, V., "Structural transition in II-VI nanofilms: Effect of molar ratio on structural, morphological, and optical properties", Journal of Applied Physics, 111(11): 113510113517, (2012).

[22] Rosales, K.R., Galvan, J.G.Q., Cervantes, A.G., Gonzalez, E.C., Cruz, J.S., Hernandez, S.A.M., Ceron, J.S.A., Olvera, M.D.L.L., Angel, O.Z., Hernandez, L.A.H., Puente, G.C., Flores, F.D.M., 
"Nanocrystalline-CdS thin films grown on flexible PET-substrates by chemical bath deposition", Materials Research Express, 4(7): 075904-075911, (2017).

[23] Cao, M., Suna, Y., Wua, J., Chena, X., Daia, N., "Effects of cadmium salts on the structure, morphology and optical properties of acidic chemical bath deposited CdS thin films", Journal of Alloys and Compounds, 508(2): 297-300, (2010).

[24] Lin, G., Zheng, J., Xu, R., "Template-free synthesis of uniform CdS hollow nanospheres and their photocatalytic activities", The Journal of Physical Chemistry C, 112(19): 7363-7370, (2008).

[25] Zhao, X.H., Wei, A.X., Zhao, Y., Liu, J., "Structural and optical properties of CdS thin films prepared by chemical bath deposition at different ammonia concentration and S/Cd molar ratios", Journal of Materials Science: Materials in Electronics, 24(2): 457-462, (2013).

[26] Lopes, P.A.L., Santos, M.B., Mascarenhasa, A.J.S., Silva, L.A., "Synthesis of CdS nano-spheres by a simple and fast sonochemical method at room temperature", Materials Letters, 136: 111-113, (2014).

[27] Tauc, J., Grigorovici, R., Vancu, A., "Optical properties and electronic structure of amorphous germanium”, Physica Status Solidi B, 15: 627-637, (1966).

[28] Kumar, R., Das, R., Gupta, M., Ganesan, V., "Compositional effect of antimony on structural, optical, and photoluminescence properties of chemically deposited $\left(\mathrm{Cd}_{1-\mathrm{x}} \mathrm{Sb}_{\mathrm{x}}\right) \mathrm{S}$ thin films", Superlattices and Microstructures, 59: 29-37, (2013).

[29] Kumar, P., Saxena, N., Chandra, R., Gao, K., Zhou, S., Agarwal, A., Singh, F., Gupta, V., Kanjilal, D., "SHI induced enhancement in green emission from nanocrystalline CdS thin films for photonic applications", Journal of Luminescence, 147: 184-189, (2014).

[30] Ji, X., Li, H., Cheng, S., Wu, Z., Xie, Y., Dong, X., Yan, P., “Growth and photoluminescence of CdS and CdS:Mn Nanoribbons", Materials Letters, 65(17-18): 2776-2778, (2011).

[31] Cruz, J.S., Perez, R.C., Delgado, G.T., Angel, O.Z., "CdS thin films doped with metal-organic salts using chemical bath deposition", Thin Solid Films, 518(7): 1791-1795, (2010).

[32] Yilmaz, S., Polat, I., Atasoy, Y., Bacaksiz, E., "Structural, morphological, optical and electrical evolution of spray deposited $\mathrm{ZnO}$ rods co-doped with indium and sulphur atoms", Journal of Materials Science Materials in Electronics, 25(4): 1810-1816, (2014). 